\title{
Disease-wide accessibility of the elderly in primary care setting: The relationship between geographic accessibility and utilization of outpatient services in Tokushima prefecture, Japan
}

\author{
Yoshimi Tsuji ${ }^{\star}$, Tomohiro Hirao ${ }^{2}$, Ai Fujikawa $^{3}$, Yoichi Hoshikawa ${ }^{4}$, Akira Yoshioka ${ }^{2}$, \\ Takeshi Yoda ${ }^{2}$, Takeshi Suzue ${ }^{2}$ \\ ${ }^{1}$ Department of Nursing, Kagawa Prefecture College of Health Sciences, Kagawa, Japan; \\ *Corresponding Author: tsuji@chs.pref.kagawa.jp \\ ${ }^{2}$ Department of Public Health, Faculty of Medicine, Kagawa University, Kagawa, Japan \\ ${ }^{3}$ Takamatsu City Public Health Center, Kagawa, Japan \\ ${ }^{4}$ Kagawa Prefectural Government, Kagawa, Japan
}

Received 8 March 2012; revised 1 April 2012; accepted 18 April 2012

\section{ABSTRACT}

In Japan, a rapid pace of aging coupled with the lower birth rates causes the decrease of the population especially in rural area, which leads to the problems with the delivery of healthcare services. We investigated the relationship between the geographical accessibility (time and distance) and the utilization rate of outpatient services in the elderly by major disease groups in Tokushima prefecture, Japan. Distances and driving times to the nearest facilities from residential sites in major disease categories were measured by using geographic information system. Utilization data was obtained from the claim data. In diseases of the musculoskeletal system and connective tissue (M00-M99), diseases of the digestive system (K00-K93), endocrine, nutritional and metabolic diseases (E00-E90), diseases of the eye and adnexa ( $\mathrm{HOO}-\mathrm{H} 59)$ and diseases of the respiratory system (J00-J99), there were moderate negative correlations (around -0.4 to -0.6 ) both in distance and time. Distance and time to the nearest facilities were important factors for the utilization of outpatient services of major disease categories in Japanese elderly. Comprehensive approach which include socioeconomic factors is needed to mitigate access problems in aging Japanese society.

Keywords: Geographic Accessibility; Aging;

Primary Care; Healthcare Utilization

\section{INTRODUCTION}

Aging is an issue that all developed countries are facing. In Japan, a rapid pace of aging coupled with the lower birth rates causes the decrease of the population especially in rural area, which leads to the problems with the delivery of social services [1-3]. Healthcare is one of the important social services which influence on the well-being of the people. In Japan universal access is guaranteed to all residents, so anyone can take healthcare services with no significant financial or geographical problems [4]. However, in rural areas the elderly may experience the difficulties in seeking healthcare services because the facilities are scarcer than in urban areas. Moving long distance to the medical facilities may lead to an inability to receive necessary treatments at right time and worsen the illnesses.

Several studies on geographic accessibility in health care have been published. Most of them investigated the accessibility of specific services, such as vaccination, pediatric care and emergency care [5-11], or some of them showed the effect on health outcome [12-15], however, disease-wide accessibility of the elderly in primary care setting was not well-investigated. To evaluate the healthcare accessibility of the elderly as a public health issue, appropriate area setting such as prefecture and considering major diseases which are popular among the elderly are required.

In this study we investigated the relationship between the geographical accessibility (time and distance) and the utilization rate of outpatient services in the elderly by major disease groups in Tokushima prefecture, Japan. We used publicly opened data from several government 
organizations. Geographical accessibility and healthcare utilization were estimated by using geographical information system and claim data of health insurance respectively. Relationships between them were analyzed by measuring coefficients of correlation.

\section{METHODS}

\subsection{Study Area}

Tokushima prefecture is located on Shikoku Island in the southwestern part of Japan. Three fourth of the land is covered by mountains and the other is narrow plain and coast areas. Its population was 810 thousand in 2005 and the population density was 195 per square kilometer. $24.4 \%$ of the population (197 thousand) was the aged 65 or more. The prefecture consisted of 50 municipalities in 2005. Most of them are located in mountainous area and have the issues of aging and a population decline. Tokushima prefecture was considered one of the typical local areas of Japan (Figure 1).

\subsection{Data Source}

In this study we defined the elderly as aged 65 years or more. We obtained 2005 population data of Tokushima prefecture in $500 \mathrm{~m}^{2}$ block level from the 2005 Population Census of Japan, reported by the Statistical Survey Department, Statistics Bureau, Japanese Ministry of Internal Affairs and Communications [16]. A list of clinics and hospitals which included address and specialties were publicly released by Tokushima prefectural government [17]. As for utilization of medical facilities, we employed the statistics of Tokushima National Health Insurance 2003 and 2004 [18,19], which included the aggregated data on age, sex and disease (major category of ICD10) specific utilization of outpatient services in May for 50 municipalities in Tokushima Prefecture. Because $88.5 \%$ of the aged 65 or more who lived in Tokushima prefecture enrolled in Tokushima National Health Insurance Organization in 2003, the data was considered the representation of the elderly in Tokushima Prefecture. We used the average of 2003 and 2004 for the analysis. The road network data for Tokushima Prefecture was derived from the National Land Numerical Information released by the National and Regional Policy Bureau, Japanese Ministry of Land Infrastructure, Transport and Tourism [20].

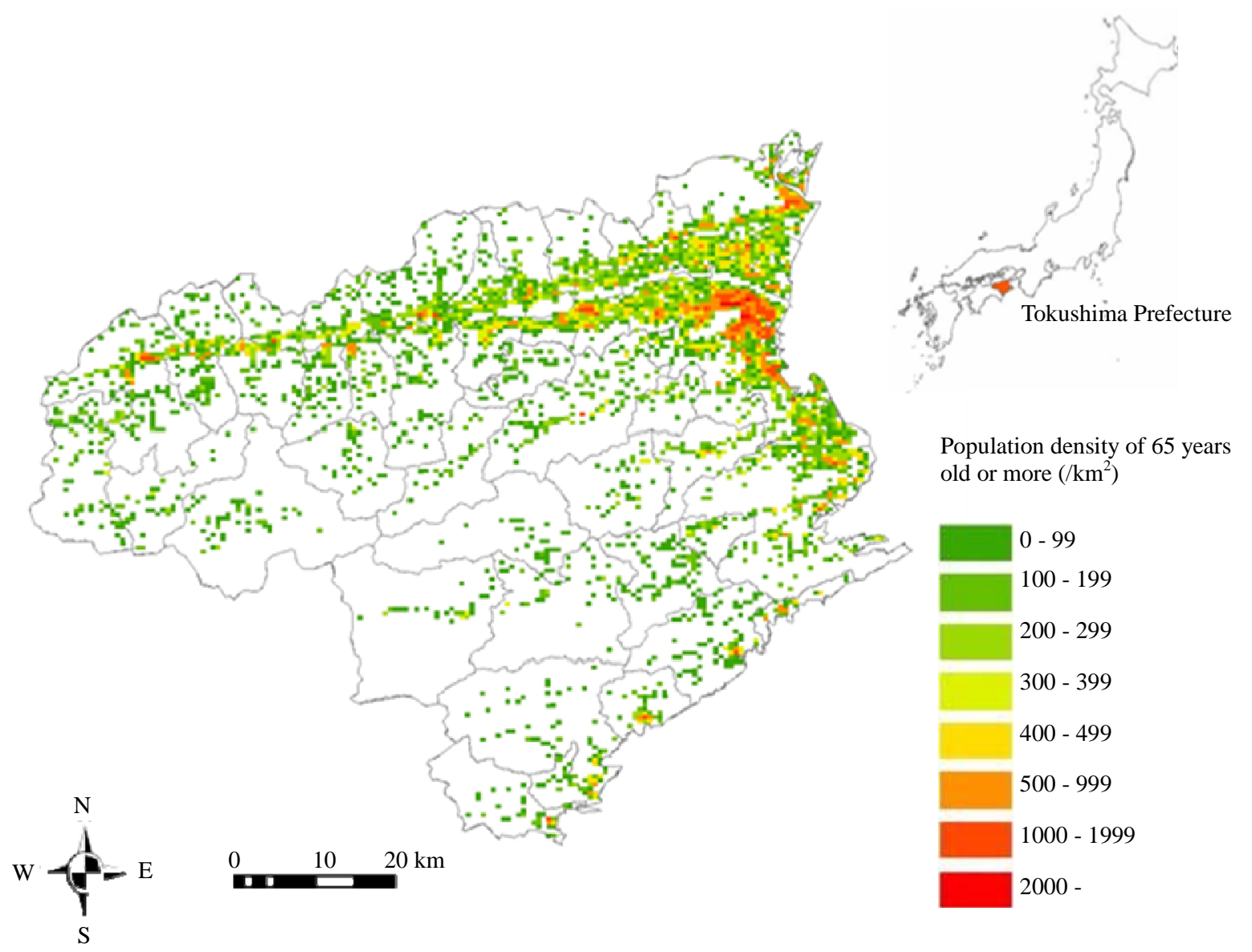

Figure 1. Distribution of the population aged 65 years or more in Tokushima prefecture. 


\subsection{Measuring Geographic Access}

Distances and driving times via normal roads between residential sites and medical facilities were measured by using geographic information system. As for residential sites we assumed all residents within $500 \mathrm{~m}^{2}$ block located at the center of the block. As for medical facilities the locations of the facilities were geocoded by using the CSV Address Matching Service supplied by the Center for Spatial Information Science at the University of Tokyo [21]. In October 2006, there were 3394 blocks and 831 medical facilities (in specialties there were 654 Internal Medicine, 202 Orthopedic Surgery, 80 Ophthalmology and 62 Psychiatry access points because several facilities had more than 2 specialties) in Tokushima Prefecture (Figure 2).

To estimate travel distance and time, we constructed digital transportation network by using digital data of road and average travel speed at the time of rush hours [22]. We specified the nearest points on the road network from center of block and the location of medical facilities; then measured the shortest routes between two points. We employed the distance and time to the nearest facility as variables of geographic accessibility. To estimate the average distance and travel time in each municipality, block level data were aggregated weighted by the population of block.

\subsection{Estimating the Utilization in the Elderly}

Data on utilization of medical facilities was provided as total sum of the days of visit in May. To estimate the age, sex, and disease specific utilization rate of outpatient services in each municipality, we employed the following equation.
Utilization rate of outpatient services per 1000 Population

$=$ Total sum of the days of visit/(Number of insured $\times 20$ days) $\times 1000$,

where 20 days means the working days of May in Japan.

Table 1 showed the utilization rate of outpatient services in major disease groups. Because 7 disease group, diseases of the circulatory system (I00-I99), diseases of the musculoskeletal system and connective tissue (M00M99), diseases of the digestive system (K00-K93), endocrine, nutritional and metabolic diseases (E00-E90), diseases of the eye and adnexa (H00-H59), diseases of the respiratory system (J00-J99) and mental and behavioral disorders (F00-F99), contributed more than $80 \%$ of total utilization, we analyzed the accessibility of these 7 disease categories.

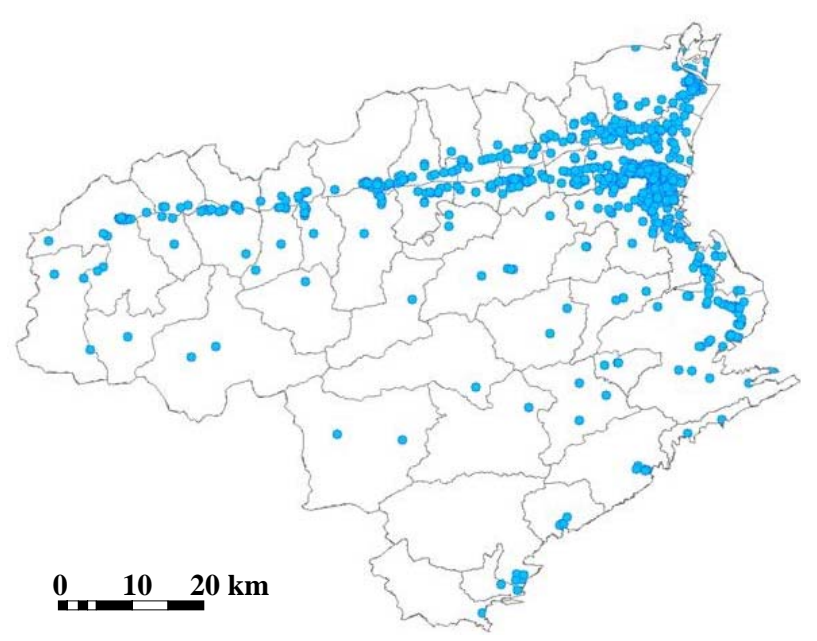

Figure 2. Distribution of medical facilities in Tokushima prefecture.

Table 1. Utilization rate of outpatient services per 1000 population aged 65 or more.

\begin{tabular}{|c|c|c|c|c|}
\hline & ICD10 & rate & $\%$ & Cumulative \% \\
\hline Diseases of the circulatory system & I00-I99 & 43.3 & $30.3 \%$ & $30.3 \%$ \\
\hline Diseases of the musculoskeletal system and connective tissue & M00-M99 & 23.5 & $16.5 \%$ & $46.8 \%$ \\
\hline Diseases of the digestive system & K00-K93 & 16.9 & $11.9 \%$ & $58.6 \%$ \\
\hline Endocrine, nutritional and metabolic diseases & E00-E90 & 12.3 & $8.6 \%$ & $67.2 \%$ \\
\hline Diseases of the eye and adnexa & H00-H59 & 8.8 & $6.1 \%$ & $73.4 \%$ \\
\hline Diseases of the respiratory system & J00-J99 & 6.8 & $4.8 \%$ & $78.2 \%$ \\
\hline Mental and behavioural disorders & F00-F99 & 6.7 & $4.7 \%$ & $82.9 \%$ \\
\hline Diseases of the genitourinary system & N00-N99 & 4.5 & $3.2 \%$ & $86.0 \%$ \\
\hline Certain infectious and parasitic diseases & A00-B99 & 4.3 & $3.0 \%$ & $89.0 \%$ \\
\hline Neoplasms & C00-D48 & 3.6 & $2.5 \%$ & $91.5 \%$ \\
\hline Injury, poisoning and certain other consequences of external causes & S00-T98 & 3.2 & $2.3 \%$ & $93.8 \%$ \\
\hline Diseases of the skin and subcutaneous tissue & L00-L99 & 2.7 & $1.9 \%$ & $95.6 \%$ \\
\hline Diseases of the nervous system & G00-G99 & 2.5 & $1.7 \%$ & $97.4 \%$ \\
\hline Diseases of the ear and mastoid process & H60-H95 & 2.0 & $1.4 \%$ & $98.8 \%$ \\
\hline $\begin{array}{l}\text { Diseases of the blood and blood-forming organs and certain disorders involving the } \\
\text { immune mechanism }\end{array}$ & D50-D89 & 0.4 & $0.3 \%$ & $99.0 \%$ \\
\hline Symptoms, signs and abnormal clinical and laboratory findings, not elsewhere classified & R00-R99 & 1.4 & $1.0 \%$ & $100.0 \%$ \\
\hline Total & & 143.0 & & \\
\hline
\end{tabular}

ICD10: International Statistical Classification of Diseases and Related Health Problems 10th Revision. 


\subsection{Analysis on the Relationship between Geographic Access and Utilization}

To investigate the relationship between geographical access and utilization, specialty of medical facilities and disease groups should be matched. According to the patient survey [23], 73.4\% of the patients with circulatory system diseases (I00-I99) visited the internal medicine, $66.0 \%$ of Diseases of the musculoskeletal system and connective tissue (M00-M99) visited the orthopedic surgery, $64.4 \%$ of Diseases of the digestive system (K00K93) visited the internal medicine, $78.7 \%$ of the patients with endocrine, nutritional and metabolic diseases (E00E90) visited the internal medicine, $98.2 \%$ of patients with eye and adnexa diseases (H00-H59) visited ophthalmology, $55.3 \%$ of the patients with Diseases of the respiratory system (J00-J99) visited internal medicine, and $67.3 \%$ of the patients with mental and behavioral disorders (F00-F99) visited the psychiatry. Therefore, we analyzed the relationship between geographical access of 4 medical specialties and utilization of 7 diseases.

In statistical analyses, coefficients of correlation were measured as the indicators of relationship and $p$ value under 0.05 was considered statistically significant. We used ArcGIS9.2 Network Analyst [24] for measuring geographic access and the JMP8 [25] for statistical analysis. All data used in this study was publicly opened.

\section{RESULTS}

Geographic accessibilities were summarized in Table 2. Among four specialties, the average distance and time to the nearest medical facilities were shortest in internal medicine, $2.7 \mathrm{~km}$ and 7.9 minutes, and the longest in psychiatry, $9.9 \mathrm{~km}$ and 20.8 minutes respectively. The distributions of variables were skewed to the right in both distance and time (Figures 3 and $\mathbf{4}$ ).

Table 3 showed the population covered within the

Table 2. Geographic access from residential area to the nearest medical facility in aged 65 or more.

\begin{tabular}{|c|c|c|c|c|c|c|c|c|c|}
\hline \multirow{2}{*}{ Specialty } & \multirow{2}{*}{ Number of facilities } & \multicolumn{4}{|c|}{ Distance (kilometer) } & \multicolumn{4}{|c|}{ Time (minute) } \\
\hline & & average & median & $\max$ & $\min$ & average & median & $\max$ & $\min$ \\
\hline Internal Medicine & 654 & 2.7 & 1.5 & 31.6 & 0.9 & 7.9 & 4.7 & 86.6 & 0.00 \\
\hline Orthopedic Surgery & 202 & 5.1 & 2.6 & 41.3 & 0.9 & 12.2 & 7.3 & 101.1 & 0.00 \\
\hline Ophthalmology & 80 & 9.3 & 4.3 & 71.8 & 5.2 & 19.7 & 11.5 & 127.6 & 0.01 \\
\hline Psychiatry & 62 & 9.9 & 5.4 & 68.3 & 5.7 & 20.8 & 13.9 & 121.9 & 0.01 \\
\hline
\end{tabular}

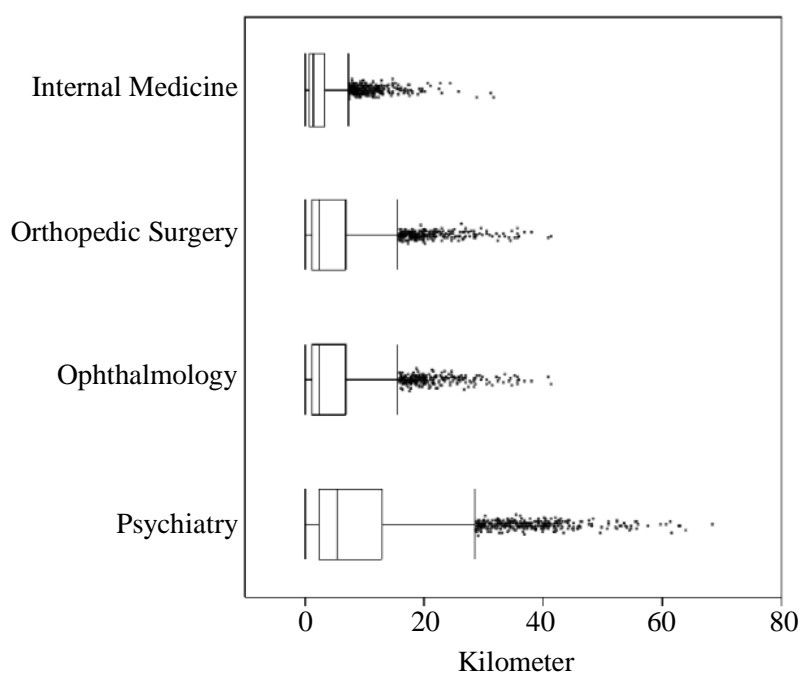

Figure 3. Boxplot of the distance to the nearest medical facilities.

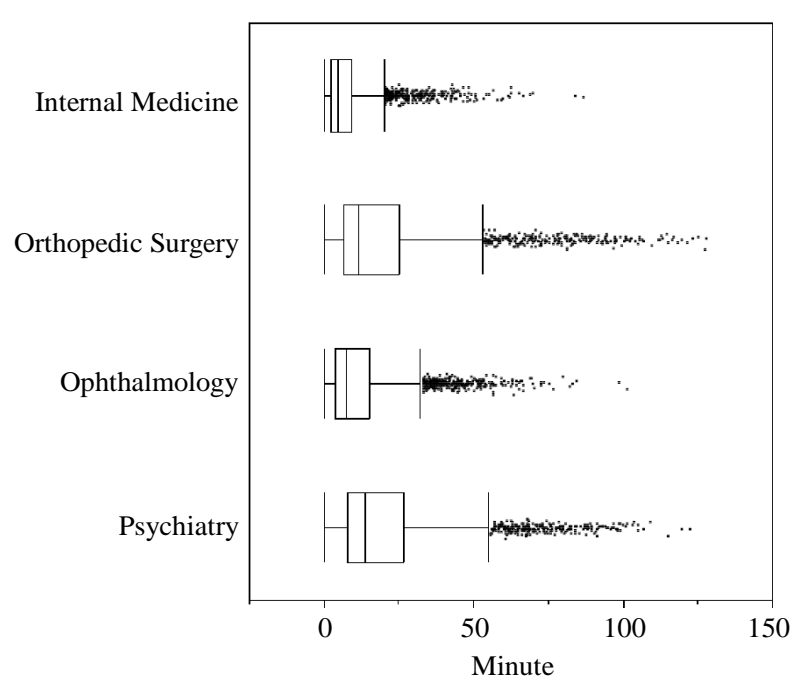

Figure 4. Boxplot of the time to the nearest medical facilities.

Table 3. Population coverage of aged 65 or more within certain distance and time from the nearest medical facility.

\begin{tabular}{|c|c|c|c|c|c|c|c|c|c|}
\hline \multirow{2}{*}{ Specialty } & \multirow{2}{*}{ Number of facilities } & \multicolumn{4}{|c|}{ Population (\%) } & \multicolumn{4}{|c|}{ Population coverage (\%) } \\
\hline & & $<5 \mathrm{~km}$ & $<10 \mathrm{~km}$ & $<15 \mathrm{~km}$ & $<20 \mathrm{~km}$ & $<15 \mathrm{~km}$ & $<30 \mathrm{~km}$ & $<45 \mathrm{~km}$ & $<60 \mathrm{~km}$ \\
\hline Internal Medicine & 654 & 94.8 & 98.9 & 99.8 & 99.9 & 95.4 & 98.9 & 99.7 & 99.9 \\
\hline Orthopedic Surgery & 202 & 86.5 & 93.4 & 96.8 & 98.9 & 89.3 & 96.7 & 99.0 & 99.7 \\
\hline Ophthalmology & 80 & 77.1 & 86.0 & 90.8 & 94.9 & 80.2 & 91.9 & 96.2 & 97.9 \\
\hline Psychiatry & 62 & 66.7 & 84.4 & 89.4 & 93.1 & 72.4 & 90.2 & 95.8 & 97.9 \\
\hline
\end{tabular}


certain distance and time. In four specialties, around $90 \%$ of the aged 65 or more was resided within $15 \mathrm{~km}$ or 30 min from the medical facilities. In internal medicine, around $95 \%$ of the aged 65 or more was resided within 5 $\mathrm{km}$ and $15 \mathrm{~min}$. Population coverage were decreased in orthopedic surgery, ophthalmology and psychiatry.

Relationship between geographic access and utilization of 50 municipalities was summarized in Table 4. In five disease groups, diseases of the musculoskeletal system and connective tissue (M00-M99), diseases of the digestive system (K00-K93), endocrine, nutritional and metabolic diseases(E00-E90), diseases of the eye and adnexa (H00-H59) and diseases of the respiratory system (J00-J99), there were moderate negative correlations (between -0.4 to -0.6 ) both in distance and time. In circulatory system diseases (I00-I99), there were weak negative correlation $(-0.267-0.205)$ but was not statistically significant. In mental and behavioral disorders (F00-F99), relationship was not detected.

\section{DISCUSSION}

The objective of this study was to understand the relationship between the geographical accessibility and the disease-wide utilization of outpatient services in Japanese elderly. We identified the moderate negative correlation between geographic accessibility and the utilization of outpatient services in five disease groups, which contributed more than half of the total visits of the elderly. Several authors reported the relationship between the geographical accessibility and service utilization in primary care settings. Nteta, et al. reported that the persons who lived within $5 \mathrm{~km}$ from community health centers were accessible and satisfied with the primary healthcare services provided [6]. Nemet, et al. investigated the relationship between distance and the utilization of health care by a group of elderly residents in rural Vermont, and reported the increased distance from provider does reduce utilization [8]. They partially supported our findings, however, our study suggested disease-wide approaches were required to mitigate the access problems of the elderly who lived in rural areas.

In mental and behavioral disorders, there was no statistically significant relation. Zulian, et al. reported the distance decay effect existed in the utilization of community-based mental health services [26]. On the other hand, Endo et al. reported there were some patient-perceived barriers to the utilization of mental healthcare services in Japanese lung cancer patients [27], and Jitsunari, et al. reported patients tended to avoid referring to mental health facilities near to the residential sites at the district level [28]. Socio-cultural factors such as relation with neighbors and/or colleagues at the worksites rather than geographic accessibility might affect the utilization of mental health services in Japanese elderly.

The other factors such as health status, car ownership and income, are well-known as the factors which affect healthcare utilization $[29,30]$. Table 5 showed the relationship between utilization and some socio-economic factors. Even the aggregated data of municipalities, annual income and pavement rate showed the positive effects on the utilizations. Single rate and employment rate of 65 or more showed the negative effect on several disease groups. These suggest the comprehensive approaches including socio-economic factors are important and further studies are needed to mitigate the access problems of the elderly who lived in rural areas.

Japan is facing the unprecedented speed of aging and the decrease of population in modern human history [31]. To secure the accessibility of healthcare services, comprehensive approach which includes the allocation of medical facilities, training of general physician and relocation of residential sites should be considered. Because most of the East Asian countries and territories, China, Rep. Korea, Taiwan and Hong Kong, will experience the same phenomenon with Japan in next 20 years [32], policies Japan chooses might be a good lesson learned in this region.

Table 4. Relationship between geographic access to the nearest medical facility and utilization rates of outpatient services in 50 municipalities of Tokushima prefecture.

\begin{tabular}{|c|c|c|c|c|c|}
\hline \multirow{2}{*}{ Disease } & \multirow[b]{2}{*}{ ICD-10 } & \multicolumn{2}{|c|}{ Distance } & \multicolumn{2}{|c|}{ Time } \\
\hline & & $\mathrm{R}$ & $P$ value & $\mathrm{R}$ & P value \\
\hline Diseases of the circulatory system & I00-I99 & -0.267 & 0.060 & -0.205 & 0.154 \\
\hline Diseases of the musculoskeletal system and connective tissue & M00-M99 & -0.592 & $<0.0001$ & -0.569 & $<0.0001$ \\
\hline Diseases of the digestive system & K00-K93 & -0.598 & $<0.0001$ & -0.535 & $<0.0001$ \\
\hline Diseases of the eye and adnexa & H00-H59 & -0.392 & 0.005 & -0.453 & 0.001 \\
\hline Diseases of the respiratory system & J00-J99 & -0.571 & $<0.0001$ & -0.462 & 0.001 \\
\hline Mental and behavioural disorders & F00-F99 & 0.024 & 0.866 & 0.013 & 0.930 \\
\hline
\end{tabular}

ICD10: International Statistical Classification of Diseases and Related Health Problems 10th Revision; R: coefficients of correlation. 
Table 5. Relationship between socio-economic factors and utilization rates of outpatient services in 50 municipalities of Tokushima prefecture.

\begin{tabular}{|c|c|c|c|c|c|c|c|c|c|}
\hline & \multirow[b]{2}{*}{ ICD-10 } & \multicolumn{2}{|c|}{$\begin{array}{l}\text { Annual income } \\
\text { (2001) }\end{array}$} & \multicolumn{2}{|c|}{$\begin{array}{l}\text { Single rate of } 65 \text { or } \\
\text { more }(2000)\end{array}$} & \multicolumn{2}{|c|}{$\begin{array}{l}\text { Employment rate of } 65 \\
\text { or more (2000) }\end{array}$} & \multicolumn{2}{|c|}{$\begin{array}{l}\text { Pavement rate } \\
\quad(2002)\end{array}$} \\
\hline & & $\mathrm{R}$ & P value & $\mathrm{R}$ & P value & $\mathrm{R}$ & P value & $\mathrm{R}$ & P value \\
\hline Diseases of the circulatory system & I00-I99 & -0.075 & 0.604 & -0.289 & 0.042 & 0.385 & 0.006 & 0.116 & 0.423 \\
\hline $\begin{array}{l}\text { Diseases of the musculoskeletal system } \\
\text { and connective tissue }\end{array}$ & M00-M99 & 0.535 & $<0.0001$ & -0.236 & 0.100 & -0.286 & 0.044 & 0.320 & 0.024 \\
\hline Diseases of the digestive system & K00-K93 & 0.477 & 0.001 & -0.409 & 0.003 & -0.125 & 0.389 & 0.367 & 0.009 \\
\hline $\begin{array}{l}\text { Endocrine, nutritional and metabolic } \\
\text { diseases }\end{array}$ & E00-E90 & 0.339 & 0.016 & -0.334 & 0.018 & -0.117 & 0.419 & 0.368 & 0.009 \\
\hline Diseases of the eye and adnexa & H00-H59 & 0.260 & 0.069 & -0.047 & 0.748 & -0.147 & 0.308 & 0.508 & 0.000 \\
\hline Diseases of the respiratory system & J00-J99 & 0.358 & 0.011 & -0.325 & 0.022 & -0.133 & 0.358 & 0.328 & 0.020 \\
\hline Mental and behavioural disorders & F00-F99 & 0.167 & 0.248 & -0.354 & 0.012 & 0.344 & 0.015 & 0.243 & 0.089 \\
\hline
\end{tabular}

ICD10: International Statistical Classification of Diseases and Related Health Problems 10th Revision; R: coefficients of correlation.

In this study we chose Tokushima prefecture as a study area which was facing the Pacific Ocean, the origin of the Nankai-Tonankai earthquakes. Historically big tsunamis hit the coastline of Tokushima prefecture several times and caused the catastrophic damage like the Great East Japan Earthquake occurred on March 11, 2011. The allocation of medical facilities is important to mitigate the burden of coming aged society, but moreover the location of residence or town itself should be a critical issue of the coast area against tsunami disasters.

There are several limitations in this study. First, because of data limitation we employed ecological study design, which makes it difficult to discuss more precisely. Second, the several factors, such as quality of care provided, severity of disease, amenity of facilities and waiting time at the facilities were not considered. Third, socio-economic factors which might affect the behaviors of utilization were not considered well. Fourth, we did not evaluate the outcome of the patients.

We demonstrated the relationship between geographic accessibility and the utilization of healthcare facilities of the elderly in Tokushima prefecture, Japan. We concluded that distance and time to the nearest facilities were important factors for the utilization of outpatient services of major disease categories in Japanese elderly. Comprehensive approach which include socio-economic factor is needed to mitigate access problems in aging Japanese society.

\section{ACKNOWLEDGEMENTS}

This study was partially supported by research grants from the Japanese Ministry of Education, Culture, Sports, Science and Technology-Japan (No.16390152) and the grant of Japanese Ministry of Health,
Labor and Welfare (H21-Iryo-Ippan-013).

\section{REFERENCES}

[1] Ogawa, N., Kondo, M. and Matsukura, R. (2005) Japan’s transition from the demographic bonus to the demographic onus. Asian Population Studies, 1, 207-226. doi:10.1080/17441730500317451

[2] Cabinet Office Japan (2009) Annual report on the aging society.

http://www8.cao.go.jp/kourei/englidssh/annualreport/200 9/2009pdf e.htm

[3] Shibuya, K. Hashimoto, H., Ikegami, N., Nishi, A., Tanimoto, T., Miyata, H., Takemi, K. and Reich, M.R. (2011) Future of Japan's system of good health at low cost with equity: Beyond universal coverage. Lancet, 378, 12651273. doi:10.1016/S0140-6736(11)61098-2

[4] Tatara, K. and Okamoto, E. (2009) JAPAN: Health System review. Health Systems in Transition, 11.

[5] Gary, H. (2004) A literature review of the use of GISbased measures of access to health care service. Health Services and Outcomes Research Methodology, 5, 119139. doi:10.1007/s10742-005-4304-7

[6] Nteta, T.P., Mokgatle Nthabu, M. and Oguntibeju, O.O. (2010) Utilization of the primary health care services in the Tshwane Region of Gauteng Province, South Africa. PloS One, 5, e13909. doi:10.1371/journal.pone.0013909

[7] Al-Taiar, A., Clark, A., Longenecker, J.C. and Whitty, C.J. (2010) Physical accessibility and utilization of health services in Yemen. International Journal of Health Gographics, 9, 38. doi:10.1186/1476-072X-9-38

[8] Nemet, G.F. and Bailey, A.J. (2000) Distance and health care utilization among the rural elderly. Social Science \& Medicine, 50, 1197-1208. doi:10.1016/S0277-9536(99)00365-2 
[9] Fu, L.Y., Cowan, N., McLaren, R., Engstrom, R. and Teach, S.J. (2009) Spatial accessibility to providers and vaccination compliance among children with medicaid. Pediatrics, 124, 1579-1586. doi:10.1542/peds.2009-0233

[10] Lee, J.E., Sung, J.H., Ward, W.B., Fos, P.J., Lee, W.J. and Kim, J.C. (2007) Utilization of the emergency room: Impact of geographic distance. Geospatial Health, 1, 243253.

[11] Hautecoeur, M., Zunzunegui, M.V. and Vissandjee, B. (2007) Barriers to accessing health care services for the indigenous population in Rabinal, Guatemala. Salud Pública de México, 49, 86-93.

[12] Yamashita, T. and Kunkel, S.R. (2010) The association between heart disease mortality and geographic access to hospitals: County level comparisons in Ohio, USA. Social Science \& Medicine, 70, 1211-1218. doi:10.1016/j.socscimed.2009.12.028

[13] Celaya, M.O. Berke, E.M. Onega, T.L., Gui, J., Riddle, B.L., Cherala, S.S. and Rees, J.R. (2010) Breast cancer stage at diagnosis and geographic access to mammography screening (New Hampshire, 1998-2004). Rural and Remote Health, 10, 1361.

http://www.rrh.org.au/articles/showarticlenew.asp?Article $\underline{\mathrm{ID}=1361}$

[14] Astell-Burt, T., Flowerdew, R., Boyle, P.J. and Dillon, J.F. (2011) Does geographic access to primary healthcare influence the detection of hepatitis C? Social Science \& Medicine, 72, 1472-1481. doi:10.1016/j.socscimed.2011.02.015

[15] De Almeida Wda, S. and Szwarcwald, C.L. (2012) Infant mortality and geographic access to childbirth in Brazilian municipalities. Revista de Saúde Pública, 46, 68-76.

[16] Statistical Information Institute for Consulting and Analysis (2008) The 2005 population census of Japan, Tokushima prefecture mesh block data. Tokyo.

[17] Medical Tokushima. http://med.pref.tokushima.jp/iryou_kenkou/search/search index.php

[18] Tokushima National Health Insurance Organization (2003) Statistics of Tokushima National Health Insurance 2003, Tokushima.

[19] Tokushima National Health Insurance Organization (2004) Statistics of Tokushima National Health Insurance 2004, Tokushima.

[20] National Land Numerical Information download service. http://nlftp.mlit.go.jp/ksj-e/index.html
[21] CSV address matching service. http://newspat.csis.u-tokyo.ac.jp/geocode/

[22] Japanese Ministry of Land (2005) Infrastructure, transport and tourism, road traffic cencus. Road Bureau, Tokyo.

[23] Ministry of Health, Labour and Welfare of Japan (1999) Patient survey 1999.

http://www.e-stat.go.jp/SG1/estat/GL08020103.do?_toGL 08020103_\&listID=000001048243\&requestSender=dsear ch

[24] Arc GIS9.2 Network Analyst. ESRI.

[25] JMP 8. SAS Institute.

[26] Zulian, G., Donisi, V., Secco, G., Pertile, R., Tansella, M. and Amaddeo, F. (2011) How are caseload and service utilisation of psychiatric services influenced by distance? A geographical approach to the study of communitybased mental health services. Social Psychiatry and Psychiatric Epidemiology, 46, 881-891. doi:10.1007/s00127-010-0257-4

[27] Endo, C., Akechi, T., Okuyama, T., Seto, T., Kato, M., Seki, N., Eguchi, K., Hosaka, T. and Furukawa, T.A. (2008) Patient-perceived barriers to the psychological care of Japanese patients with lung cancer. Japanese Journal of Clinical Oncology, 38, 653-660. doi:10.1093/jjco/hyn088

[28] Jitsunari, F., Asakawa, F., Utsumi, T., Shiraishi, H., Manabe, Y., Goto, A. and Nakajima, T. (1989) Utilization of mental healthcare in the elderly. Journal of Shikoku Public Health Society, 34, 150-157.

[29] Arcury, T.A., Gesler, W.M., Preisser, J.S., Sherman, J., Spencer, J. and Perin, J. (2005) The effects of geography and spatial behavior on health care utilization among the residents of a rural region. Health Services Research, 40, 135-155. doi:10.1111/j.1475-6773.2005.00346.x

[30] Comber, A.J., Brunsdon, C. and Radburn, R. (2011) A spatial analysis of variations in health access: Linking geography, socio-economic status and access perceptions. International Journal of Health Geographics, 10, 44. http://creativecommons.org/licenses/by/2.0

[31] Muramatsu, N. and Akiyama, H. (2011) Japan: Superaging society preparing for the future. The Gerontologist, 51, 425-432. doi:10.1093/geront/gnr067

[32] Chan, A. (2005) Aging in Southeast and East Asia: Issues and policy directions. Journal of Cross-Cultural Gerontology, 20, 269-284. doi:10.1007/s10823-006-9006-2 